\title{
NSF gets a pat on the back in report suggesting stronger industrial ties
}

\begin{abstract}
Washington. US academic scientists can take comfort from a report issued last week that says the National Science Foundation (NSF) is not broken and does not need to be fixed by shifting more of its budget into applied research. The report, by a Commission on the Future of NSF, applauds everything that NSF is doing with its \$2-billion research budget and urges NSF officials to work harder at explaining how basic research eventually benefits society.
\end{abstract}

Many were troubled when Walter Massey, the NSF director, announced in August that the National Science Board was forming a 15-member commission of prominent academic and business leaders to examine how NSF might play a larger role in strengthening the US economy (see Nature 358, 611; 1992). Coming on the heels of a suggestion from a committee of the US Congress that NSF should help the country to regain economic preeminence, there was concern that the foundation might begin making large grants to industrial scientists and reduce its traditional emphasis on investigator-initiated basic research. Despite three public meetings during which members went to great lengths to disavow such intentions (see Nature 359, 261; 1992), many were waiting anxiously to read the report itself.

What they will find is 11 pages of praise for NSF's current activities and its mission to support academic research and improve science and mathematics education. To be sure, there is room for improvement: NSF should support more interdisciplinary research, work more closely with industry and evaluate more carefully the outcomes of research it funds. NSF's priorities should be linked to a broader national mission, the report emphasizes, and NSF's advisory body, the National Science Board (NSB), should play a larger role in setting those targets. But the report emphasizes that science is not to blame for the difficulties facing US industry, saying that "failures in the market place have not been the result of a slow transfer of academic science to industry".

The report is likely to placate critics in Congress concerned that NSF is not doing enough to help the country without jeopardizing its role as a primary source of funding for academic researchers outside the biomedical sciences. Stanford chemist Richard Zare, a NSB member, ruled out any change in the status quo by asking if the report proposes direct funding of industrial research and being told by William Danforth, co-chair of the commission and chancellor of Washington University in St Louis, Missouri, that "it's not on anybody's agenda".

Another important audience for the report is industrial researchers and corporate leaders. The commission's other cochair, Robert Galvin, the former head of Motorola Inc., says that the three-month effort opened his eyes to NSF's value as an untapped resource for industry.

As an example, Galvin draws attention to a recommendation by the commission that more industrial scientists should serve on NSF advisory committees and accept temporary assignments at the foundation. Such 'rotators' are predominantly from universities, however, and Galvin confessed that it had never occurred to him that one of the company's scientists might work for a few years at NSF. The report has changed his thinking, says Galvin. Similarly, Galvin hopes the report will convince other industrial leaders to pay closer attention to what NSF is doing and to provide matching funds for collaborative research.

Although the report does not contain numbers, it says that its proposals will require a larger NSF budget. If the federal government cannot provide such an increase, NSF should reallocate existing programmes to reflect national needs. At the same time, it suggests that NSF should seek more money from industry "to complement public funding for selected science, engineering and technology programs".
The report avoids discussing what NSF's research priorities should be, with Galvin and Danforth emphasizing that the commission lacked sufficient time and expertise to do so. That is an important difference from the 18-month exercise being conducted by the National Institutes of Health, which has compiled several hundred pages listing which areas of biomedical research are most deserving of support. That exercise, including five public hearings around the country, has touched off loud debates; in contrast, the NSB commission says that such details are best handled by NSF officials in the course of their work.

The commission, having delivered its report on time, will be dissolved and its findings will form the basis of discussion within the science board over the next several months. Although Congress has asked Massey to incorporate relevant portions of the report into an operating plan for 1993 that he must submit on 15 December, it is doubtful whether its recommendations will significantly alter the foundation's present direction. A more likely target is the foundation's budget for the 1994 fiscal year beginning on 1 October 1993, which will emerge in February as part of the first budget submitted by President-elect Bill Clinton.

Jeffrey Mervis

\section{Sakmann starts German-Israeli fund}

Munich. Last year's Nobel prizewinner for physiology and medicine has donated much of his prize money to create an annual lecture tour for young scientists in Israel and Germany. The gesture is one more sign of

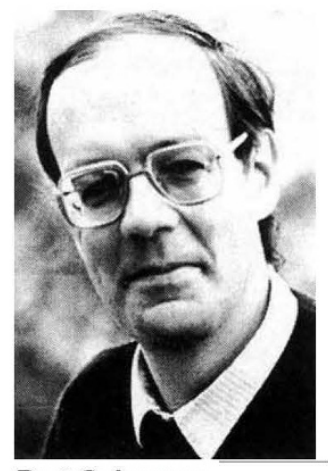

Bert Sakmann increasing scientific cooperation between the two countries.

For German electrophysiologist Bert Sakmann, who shared the 1991 Nobel Prize with Ernst Neher for their invention of the patchclamp technique, the DM150,000 (US $\$ 100,000$ ) endowment was an opportunity to reinforce links to the past. "We still want to do something for Israel, especially for young scientists", he says.

The lectureship is named after his mentor Bernard Katz, a physiologist forced to leave
Germany in the 1930s who established strong scientific links - particularly in cell physiology - with Israel after the war. Sakmann studied with Katz at University College London.

A second inspiration was Wilhelm Feldberg, a physiologist who was also forced to emigrate from antisemitic prewar Germany. Feldberg used the compensation given to him by the German government to found the Feldberg lecture series based in Britain.

Relations between German and Israeli scientists have been improving since the early 1960s, when Germany's Max Planck Society and Israel's Weizmann Institute established the Minerva Foundation to administer a joint programme of research. The German-Israeli Foundation (GIF) was established in 1988 with DM150 million contributed by the two governments.

The Bernard Katz lectureship is open to young German and Israeli cell physiologists and biophysicists. The award, which will alternate between the two fields, provides money for them to visit colleagues in the other country. 